\title{
QUALIDADE DE VIDA DA CRIANÇA COM INSUFICIÊNCIA RENAL CRÔNICA
}

\author{
Life quality of children with chronic renal failure \\ Cualidad de vida de niños con insuficiencia renal crónica
}

Mirna Albuquerque Frota ${ }^{1}$

Juliana da Costa Machado²

Mariana Cavalcante Martins ${ }^{3}$

Viviane Mamede Vasconcelos ${ }^{4}$

Fátima Luna Pinheiro Landin ${ }^{5}$

\section{RESUMO}

0 estudo objetivou avaliar a qualidade de vida de crianças com insuficiência renal crônica e identificar os domínios mais relevantes. É descritivo, com abordagem qualitativa e quantitativa, para a qual se utilizou a aplicação do Autoquestionnaire Qualité de Vie Enfant Imagé (AUQEI). Realizado no Instituto do Rim, em Fortaleza-CE-Brasil, com 13 crianças com diagnóstico de insuficiência renal crônica. Os dados foram analisados por meio da técnica de análise temática e do programa estatístico EXCEL. Emergiram as categorias: Dor no momento da diálise; Hospitalização; Limitações da doença e tratamento; Expectativa do transplante; e Apoio/aproximação familiar. A análise dos dados indicou que $61,53 \%$ das crianças possuem qualidade de vida regular, enquanto $38,46 \%$ têm essa qualidade prejudicada. As dimensões mais representativas foram: Lazer e Família, sendo Autonomia a dimensão mais comprometida. A qualidade de vida de criança com insuficiência renal crônica é considerada satisfatória, apesar das limitações.

Palavras-chave Qualidade de Vida. Saúde da Criança. Insuficiência Renal.

\begin{abstract}
The study aimed to evaluate the life quality of children with chronic renal failure and identify the most relevant areas. It is descriptive, qualitative and quantitative, for which we used the implementation of Autoquestionnaire Qualité de Vie Enfant Image (AUQEI). Held at the Kidney Institute, in Fortaleza-CE-Brazil, with 13 children diagnosed with chronic renal failure. The data were analyzed using the technique of thematic analysis and statistical program EXCEL. Categories emerged: Pain at the dialysis time; Hospitalization; Limitations of the disease and treatment; Transplant expectancy; and Support/family support. The data analysis indicated that $61.53 \%$ of children have a regular quality of life, while $38.46 \%$ have this quality impaired. The dimensions were the most representative: Recreation and Family, being Autonomy the dimension most affected. The quality of life of children with chronic renal failure is considered satisfactory, despite the limitations.
\end{abstract}

Keywords: Quality of life. Child Health. Renal Insufficiency.

\section{Resumen}

El objetivo del estudio fue evaluar la cualidad de vida de niños con insuficiencia renal crónica e identificar los dominios más importantes. Es descriptivo, con abordaje cualitativo y cuantitativo, donde se utilizó la aplicación del Autoquestionnaire Qualité de Vie Enfant Imagé (AUQEI). Realizado en el Instituto del Riñón, en Fortaleza-CE-Brasil, con 13 niños con diagnóstico de insuficiencia renal crónica. Los datos fueron analizados a través de la técnica de análisis temática y del programa EXCEL. Emergieron las categorías: Dolor en el momento de la diálisis; Hospitalización; limitaciones de la enfermedad y tratamiento; expectativa del trasplante; y apoyo/aproximación familiar. El análisis de los datos indicó que $61,53 \%$ de los niños poseen una cualidad de vida regular, mientras $38,46 \%$ tienen esta cualidad perjudicada. Las dimensiones más representativas fueron: entretenimiento y familia, siendo la autonomía más afectada. La cualidad de vida de los niños con insuficiencia renal crónica es considerada satisfactoria, a pesar de las limitaciones.

Palabras clave: Cualidad de vida. Salud del niño. Insuficiencia Renal

\footnotetext{
Doutora em enfermagem. Docente da Graduação em Enfermagem e do Mestrado em Saúde Coletiva da Universidade de Fortaleza - UNIFOR.Fortaleza-CE- Brasil. E-mail: mirnafrota@unifor.br, , ${ }^{2}$ Enfermeira. Hospital Geral de Fortaleza.Fortaleza-CE-Brasil. E-mail: jhuly_machad@hotmail.com, ${ }^{3}$ Mestra em Saúde Coletiva. Discente do curso de Doutorado em Enfermagem pela Universidade Federal do Ceará - UFC. Bolsista da CAPES. Fortaleza-CE-Brasil. E-mail: marianaenfermagem@hotmail.com, ${ }^{4}$ Discente do curso de Mestrado em Saúde Coletiva da Universidade de Fortaleza - UNIFOR. Bolsista da FUNCAP. Fortaleza-CEBrasil. E-mail: vivienfermagem@hotmail.com, ,Doutora em enfermagem. Docente da Graduação em Enfermagem e do Mestrado em Saúde Coletiva da Universidade de Fortaleza - UNIFOR.Fortaleza-CE-Brasil. E-mail: llunna@terra.com.br
} 


\section{INTRODUÇÃO}

A Insuficiência Renal Crônica (IRC) consiste na perda progressiva e irreversível das funções renais, que pode iniciar com um quadro agudo ou de maneira lenta. 0 tratamento definitivo indicado é o transplante renal. Trata-se de processo moroso, e, até que se concretize, a alternativa para manter a vida está no tratamento dialítico contínuo, que compreende duas modalidades - diálise peritonial e hemodiálise. ${ }^{1}$

Segundo censo realizado pela Sociedade Brasileira de Nefrologia, em janeiro de 2007, estima-se que haja 73.605 pacientes mantidos em programas dialíticos, sendo 90,8\%(66.833) em hemodiálise e 9,2\% (6.772) em diálise peritonial. ${ }^{2}$

Avanços tecnológicos trouxeram melhora significativa para o tratamento da IRC; entretanto, este ainda apresenta riscos que aumentam proporcionalmente os índices de morbidades emocionais e físicas, não somente pela gravidade da doença, por não ter cura, mas especialmente pelas limitações e pela mudança abrupta na rotina para sua efetivação. 0 tripé sustentador do tratamento conservador é constituído por diálise, dieta e drogas medicamentosas. A aderência a essa tríade terapêutica promove estado de controle hidroeletrolítico essencial para a sobrevida desses pacientes. ${ }^{3}$

A diálise, terapia renal substitutiva, tem a finalidade de melhorar a qualidade de vida (QV) dos pacientes, pelo fato de reaver o bem-estar físico e a capacidade cognitiva, além de manter a inserção no contexto social. 4 Em contrapartida, essa proposta pode esbarrar nas alterações da vida diária que 0 tratamento hemodialítico desencadeia, pela falta de suporte familiar e da equipe de saúde para a manutenção do tratamento e, consequentemente, pode ocasionar um impacto na qualidade de vida. ${ }^{5}$

O IRC, que deve ser submetido a diálise, inclui rigidez dietética e de horário, mudanças potenciais nos contextos familiar, ocupacional e social, bem como preocupações diversas com a doença e seu tratamento, fazendo com que muitos dos pacientes encontrem dificuldades em se adaptar à doença, suas consequências e incerteza do futuro. ${ }^{3}$

Na realidade infantil, suas repercussões são ainda mais graves, pois requerem atenção diferenciada. A criança passa por alteração relacionada ao crescimento e desenvolvimento. Quando portadora de doença crônica, como IRC, as transformações são particularmente incômodas em decorrência das limitações impostas pela doença.

As alterações da saúde da criança, em especial no que se refere às consequências da insuficiência renal crônica, desencadeiam estresse, desorganizam sua vida, atingem a autoimagem, bem como mudam o modo de perceber a vida. As transformações físicas e psicossociais alteram a aquisição do controle progressivo sobre o próprio corpo e redimensionam seu mundo. A criança com IRC percebe-se excluída do contexto das outras, descobre-se comprometida, obrigada a se adaptar às intervenções terapêuticas, o que as impede de desfrutar da liberdade comum à infância. ${ }^{6}$

Desde muito pequenas, compreendem a necessidade de enfrentar exames e procedimentos, assumindo atitude cooperativa, apesar do desconforto e da dor. Utilizam mecanismos adaptativos que as capacitam para enfrentar as intervenções e facilitam a relação com as diferentes pessoas que continuamente entram no quarto, tocam seu corpo, examinam seus aparelhos, determinam atitudes, impedem ações. ${ }^{7}$

Dessa forma, precocemente alteram seu processo de se conhecer, amadurecem, compreendem e experimentam suas limitações, refletindo na sua percepção de qualidade de vida, sendo esta uma noção eminentemente humana, que tem sido aproximada ao grau de satisfação encontrado na vida familiar, amorosa, social e ambiental e à própria estética existencial.

A expressão qualidade de vida (QV) abrange muitos significados, que refletem conhecimentos, experiências e valores de indivíduos e coletividades que a ele se reportam em variadas épocas, relacionados com o seu funcionamento diário, sendo, portanto, uma elaboração social com a marca da relatividade cultural. $^{8}$

Neste contexto, objetivou-se avaliar a qualidade de vida de crianças com insuficiência renal crônica, bem como identificar os domínios mais relevantes.

\section{PROCEDIMENTO METOLÓGICO}

Trata-se de um estudo descritivo, com abordagem qualitativa e quantitativa, pois essa relação entre subjetividade e objetividade não se reduz a um continuum, portanto, não pode ser pensada como oposição contraditória. Assim, o estudo quantitativo pode ensejar questões para serem aprofundadas qualitativamente, e vice-versa. ${ }^{9}$

A pesquisa foi realizada no Instituto do Rim, serviço de hemodiálise e diálise peritonial da cidade de Fortaleza, Ceará, Brasil. Os participantes da pesquisa foram 13 crianças com diagnóstico de Insuficiência Renal Crônica em Terapia Renal Substitutiva, correspondendo a 92,85\% das crianças atendidas na instituição referida, no período da realização do estudo. Ressalta-se que se delimitou idade superior a 4 anos e inferior a 12, independentemente do sexo, baseado no que preconiza o Estatuto da Criança e do Adolescente, segundo o qual a pessoa com até 12 anos de idade incompletos é considerada criança. ${ }^{10}$ A escolha desse limite de idade baseou-se no fato de 0 instrumento utilizado destinar-se a crianças nessa faixa etária.

A coleta de dados foi realizada no período de janeiro a abril de 2008, tendo sido utilizado o instrumento Autoquestionnaire Qualité de Vie Enfant Imagé (AUQEI). 0 AUQEI possibilita uma autoavaliação que utiliza o suporte de imagens para que a criança responda a cada questão, 
apresentando um domínio e quatro respostas, sendo representadas com o auxílio de faces que exprimem diferentes estados emocionais que correspondem a muito infeliz, infeliz, feliz e muito feliz. ${ }^{11}$ Esse instrumento é composto de quatro perguntas subjetivas e 26 questões objetivas que exploram as relações familiares, sociais, atividades, saúde, funções corporais e separação, direcionadas a crianças de 4 a 12 anos de idade.

Nas questões subjetivas do AUQUEI, são feitas as indagações: "Algumas vezes você está muito infeliz? Diga por quê"; "Algumas vezes você está infeliz? Diga por quê", "Algumas vezes você está muito feliz? Diga o porquê", "Algumas vezes você está feliz? Diga por quê". Neste momento, uma das pesquisadoras mostrou as quatro faces do AUQEI para facilitar a compreensão. Nas 26 questões objetivas, a criança assinalou a resposta dentre as quatro opções, qual representa melhor seu sentimento diante da questão.

Essas questões/domínios exploram relações familiares, sociais, atividades, saúde, funções corporais e separação; 18 delas contidas em quatro fatores ou dimensões, assim distribuídas. Função: questões relativas a atividades na escola, às refeições, ao deitar-se e a ida ao médico (questões 1;2;4;5;8); Família: questões relativas à opinião quanto às figuras parentais e delas quanto a si mesmas (questões 3;10;13;16;18); Lazer: questões relativas a férias, aniversário e relações com os avós (questões 11;21;25); Autonomia: questões relacionadas a independência, relação com os companheiros e avaliação (questão 15;17;19;23;24). E outras oito questões de números 6, 7, 9, 12, 14, 20, 22 e 26 detêm importância isolada, pois representam domínios separados dos demais.

Para analisar, cada uma das respostas tem um escore específico 0, 1, 2, 3 que correspondem a muito infeliz, infeliz, feliz e muito feliz, respectivamente, o que possibilitou a obtenção de escore único, resultante do somatório dos escores atribuídos aos itens. Quanto maior o escore obtido, melhor a qualidade de vida da criança. Um ponto de corte abaixo de 48 (pontuação) das crianças estudadas pode ser considerado prejudicado. Foi utilizado o programa estatístico EXCEL, versão 2003.

Na abordagem qualitativa, em que as respostas foram obtidas por meio das questões subjetivas do AUQUEI, optou-se por adotar a técnica da análise temática de Minayo, ${ }^{12}$ pois procura obter os núcleos de sentido, ou seja, os temas mais significativos abordados nas falas.

0 projeto de pesquisa foi submetido à apreciação do Comitê de Ética em Pesquisa da Universidade Fortaleza UNIFOR, tendo sido aprovado sob o Parecer Nº. 372/2007 (Anexo 2). Ressalta-se que, com a anuência das crianças e de seus responsáveis, firmavam-se as participações com as respectivas assinaturas. Assim, no sentido de resguardar suas identidades, os sujeitos foram identificados por cognomes (C1, C2... C13).

\section{RESULTADOS E DISCUSSÃO}

\section{Características dos sujeitos}

A idade das crianças variou entre 4 e 12 anos, assim distribuída: seis tinham 12 anos de idade; dois, 10 anos; um de cada idade, 11, 9, 7, 5 e 4 anos. Quanto ao sexo, sete eram do feminino e seis, do masculino. Dois procediam de Fortaleza-CE, cinco da região metropolitana e os outros seis vieram de outras cidades do Ceará (uma delas mudou-se definitivamente para Fortaleza-CE). Quanto à escolaridade das crianças, cinco não haviam iniciado a alfabetização, quatro não retornaram à escola após o início do tratamento e três estavam cursando o ensino fundamental, embora uma destas não o frequente regularmente.

\section{AUQEI Qualitativo}

Como resultado da aplicação das quatro perguntas subjetivas do AUQEI e análise temática, emergiram as categorias: Dor no momento da diálise; Conflito da hospitalização; Limitações da doença e tratamento; Expectativa do transplante e Apoio/aproximação familiar.

\section{Dor no Momento da Diálise}

A criança com insuficiência renal crônica passa a depender obrigatoriamente de terapêuticas que assumem a função corporal perdida (hemodiálise-HD e CAPD-diálise peritonial continua), procedimentos esses que prolongam, mas que sobretudo alteram a qualidade de vida. Crianças em HD convivem com tubos entrando e saindo da pele, assistem ao sangue circulando fora do corpo e aprendem que é necessária a presença da máquina, como suporte de vida externa, para o bom funcionamento do organismo. Dialisar significa por a vida nas mãos de uma equipe muldisciplinar e, mais ainda, depender de uma máquina-objeto externo que salva, mas limita e restringe. ${ }^{13}$

Detectou-se o fato de que, das treze crianças, oito mencionaram o quão doloroso é o processo da diálise. São relatos significantes dentro do mundo vivenciado por essas crianças, dos sentimentos gerados pela dor e do amadurecimento causado por ela. Fatores como dor, pela enfermidade, ou tratamento ou falta de energia para aproveitar as atividades do cotidiano foram relatados:

Por que as vezes eu sinto dor na cabeça. Quando eu estou aqui também por que eu sinto dor no cateter e às vezes tem que mexer no cateter, ele inflama, dói (...)(C13-10 anos)

Por causa da doença, quando acontece alguma coisa errada com esse cateter velho, eu quero logo é colocar a fistula (...) Eu não posso brincar, eu caio em pé, tô fraquinha (...) (C5-12 anos)

Crianças com IRC não só são portadoras de doenças crônicas, mas, sobretudo, de estilo de vida crônico em virtude da submissão obrigatória a procedimentos terapêuticos. 
Limitações são impostas pela doença: restrição hídrica, dietas, ocupação, lazer; há uma mudança no estilo de vida da criança. Muito precocemente, essas crianças assumem responsabilidades/maturidade sobre a patologia e sobre o que é permitido ou não realizar. Relatam sintomas e informaç̃̃es sobre a doença e quando é necessário intervir na diálise.

Durante a aplicação do AUQUEI, foi observado que C1, de 4 anos de idade, sentiu-se mal e solicitou que a auxiliar de enfermagem administrasse soro, medida utilizada para aliviar os sintomas da diálise, e posteriormente necessitou de medicação:

Senti dor, dor no cateter, dor de cabeça e pedi soro (...)(C1-4 anos)

Relato caracterizado pela maturidade da criança que teve amadurecimento precoce.

Essas transformaç̧̃es vão além de um campo de conhecimento e implicam vivências diárias, carregadas de marcas que a patologia imprime na vida da criança, fazendonos entender que há repercussões na maneira como a criança com doença crônica se apresenta e se relaciona com o mundo. A doença crônica é intrinsecamente parte da identidade. ${ }^{7}$

\section{Hospitalização}

Essa categoria emergiu diante do cotidiano das crianças, pois os aspectos inerentes no ambiente hospitalar são vários, como o próprio ambiente físico, procedimentos invasivos, interrupção das atividades cotidianas, entre outros, em que o estado de privação da família é significativo durante esse processo.

Assim, a internação hospitalar traduz-se em experiência difícil para o paciente, ocasionando ansiedade pela exposição da criança a uma esfera estressante, sendo restrito 0 apoio para o enfrentamento destes sentimentos, de tal forma que uma das poucas fontes de segurança é representada pelos pais. $^{14}$

Quando estou no hospital naquela cama velha, deitado direto, fico muito tempo longe dos meus pais, eles que me cuidam muito (...) (C10 - 12 anos);

Quando ta no hospital por que é muito ruim, sentido dor na barriga (C9 - 12 anos);

Por que quando eu estou no hospital leva muita picada, picada no pé, da injeção para levar remédio (...)(C12-12 anos).

A vida da criança ao ingressar no hospital é marcada por momentos de angústia e insegurança que vão repercutir na vida, além da alta hospitalar. 0 impacto é significativo para as crianças de menor idade. Naquele momento, encontra-se excluída do meio, depara-se com um clima hostil, sendo presente o anseio de alta hospitalar, para, então, se encontrar em espaço íntimo/familiar. Com efeito, a criança fica alerta a qualquer movimento que possa sugerir a realização do procedimento, tornando-se angustiante, uma vez que a despreocupação é própria da infância.

Quando eu tenho dor e estou sozinho, sem a mãe, quando estou no Hospital e não tira a veia do pé pra eu ir embora (...) (C8-5 anos).

A vulnerabilidade da criança na vivência da experiência da hospitalização compõe-se de categorias que descrevem as várias facetas do sofrimento vivenciado. Abrange aspectos inevitáveis da experiência e as dificuldades que a acompanham, como a convivência com a dor e o mal-estar, a submissão a restrições, a exploração do corpo e a realização de procedimentos dolorosos, invasivos e desconhecidos.

\section{Limitações da Doença e Tratamento}

Quando em a,mbiente hospitalar e tratamento da diálise, 0 ato de brincar, momento em que a criança interage com o meio e desenvolve a função social, é comprometido pelos limites do tratamento.

Por causa da doença, é porque eu não posso brincar, fico só sentada lá fora (C5-12 anos).

Assim, o ambiente de casa é um espaço terapêutico que é capaz de promover a continuidade do desenvolvimento infantil. Independentemente do lugar e como esse processo acontece, é momento agradável, que minimiza a tensão, repleto de possibilidades e sem objetivos definidos.

Brinco, quando eu saio de casa e brinco com meus amigos, quando pode. (C6-12 anos)

Fico feliz, quando eu vou brincar com meu pai e quando minhas amigas vêm pra cá (...) (C7 - 7 anos).

Fico feliz quando estou fora daqui, quando eu saio, estou brincando com meus amigos (...) (C4 - 9 anos).

0 contexto no qual a criança brinca determina a maneira como interage na sociedade. A escola consiste no espaço por excelência, pois é onde a criança passa importantes momentos da vida e desenvolve as primeiras habilidades sociais e intelectuais. ${ }^{15}$ É nesse ambiente que a criança mantém vínculos, ampliando o espaço para outras possibilidades, brincadeiras, aprendizagem, incluindo-se em grupos. Em razão do tratamento, porém, muitas vezes, 
necessitam ausentar-se desse local, o que acarreta atraso e prejuízo ao aprendizado.

Fico muito feliz quando eu podia comer pastel. Quando eu estava na escola. Porque pode. Tinha tarefa.(C11-12 anos).

Fico triste porque eu não vou mais pra escola, porque às vezes eu sinto dor no cateter. (C3-10 anos).

Fico feliz quando eu andar de bicicleta e também quando eu aprender a ler e a escrever e ser igual aos outros. Brincar também, porque vai estar junto das outras crianças, meninas da escola. (C12-12 anos).

0 ritmo de vida da criança é alterado, pois se anteriormente a doença a prioridade era brincar, pular, jogar futebol, surgem as restrições, sendo necessário redobrar os cuidados para não sofrer traumas, o que pode gerar exacerbação dos sintomas e comprometimento do quadro clínico; é preciso reprimir desejos entre a vontade de comer e poder fazê-lo.

\section{Expectativa do Transplante}

Ao questionar quando ficaria feliz, outro aspecto mencionado foi a possibilidade de conseguir um transplante, sendo caracterizado como fator indispensável para a obtenção de boa qualidade de vida. A expectativa da mudança no estilo de vida foi expressa como sendo a ponte para exercer atividades comuns à maioria das crianças.

Quando acontecer de eu colocar os rins e ser muito feliz. De ter uma vida normal (...). (C5 - 12 anos).

Já fiquei muito feliz sim, por que teve a chance do transplante, de eu não precisar mais vim pra cá. Vai ficar boa pra sempre (...). (C12-12 anos).

Verificou-se a intenção de não ter mais que se submeter à diálise, às dolorosas punções (da fistula arteriovenosas), quase que diárias, de não mais necessitar da máquina para manter a vida, o desejo de poder se comportar como qualquer outra criança da sua faixa etária, criando uma expectativa na mudança de estilo de vida, que poderá ser proporcionado com o transplante.

Foi verificado ainda o relato de desejo de estudar, de poder brincar e principalmente de crescer e se desenvolver, já que a doença e o tratamento limitam o desenvolvimento infantil, ensejando mais expectativas de ter a vida "normal", após o transplante:

Porque às vezes ficam falando que eu sou feia, sou pequena e da cabeça grande. Dizem que sou jumenta por que não consigo estudar. Vou ficar feliz quando eu for igual aos outros (...) (C12 - 12 anos).

Se eu pudesse fazer 5 dias de máquina pra poder ser 5 dias sem, quando eu ficar de férias da diálise (...). (c8-5 anos).
Observou-se que, sob o olhar da criança, a diálise tem característica de dualidade, pois, ao mesmo tempo em que traz sofrimento, a mantém viva como alternativa para a expectativa do transplante.

Assim, ante tal esperança, sabe-se que preparar as crianças para um tratamento que lhes permita uma vida com qualidade, criar mecanismos que os ajudem a transpor as barreiras provocadas pela doença e consequente tratamento, nem sempre é uma tarefa simples, e, diante de um sonho, o transplante é um caminho longo e demorado, e seus resultados nem sempre condizem com o que foi sonhado pela criança e pela família. ${ }^{16}$

Em caráter complementar, durante a coleta de dados, a criança C 12 foi contemplada com a possibilidade de realizar o transplante renal, mas, por motivos de interesses financeiros do responsável, este não foi realizado, ocasionando frustração e decepção na criança e na equipe da instituição. 0 familiar utilizava-se da criança para adquirir recursos, pois as pessoas se solidarizavam com a situação, fazendo doações, de forma que, caso a criança realizasse o transplante, impossibilitaria que essas ações em benéfico da criança permanecessem.

Diante dessa situação se faz necessário evidenciar o Estatuto da Criança e do Adolescente no Art. 5. :

"Nenhuma criança ou adolescente será objeto de qualquer forma de negligência, discriminação, exploração, violência, crueldade e opressão, punido na forma da lei qualquer atentado, por ação ou omissão, aos seus direitos fundamentais"10:10.

Portanto, no caso supracitado, o familiar cometeu negligência, exploração, opressão e omissão ao direito de viver da criança. No entanto, apesar de termos ciência que é dever da família, da sociedade e do estado respeitar os direitos fundamentais da criança, faz-se necessário repensar nas condutas relacionadas não somente ao apoio social/familiar, mais também na prática profissional.

\section{Apoio/Aproximação Familiar}

A presença dos pais e familiares as conforta e as deixa felizes, pois compartilham os medos, buscam apoio para enfrentar e minimizar a dor, tornando referencial.

Porque quando eu estou com minha mãe e com meu pai, eu não estou doente. Minha mãe faz bem pra mim (...). (C13-10 anos).

Quando o meu pai chega de viagem e eu brinco com ele. (C7-7 anos).

Quando brinca com a Bibi e com a Cacá (irmãs). (c1- 4 anos) 
Na maioria das vezes, a pessoa numa condição de portador crônico de alguma patologia necessita compartilhar este enfrentamento com a família ou com outras pessoas próximas, buscando ajuda e apoio, pois esta situação requer adaptação individual e familiar. ${ }^{17}$

\section{AUQEI Quantitativo}

Com base em uma variação possível de 0 a 78, considerando-se como nota de corte 48, estabelecida por Assumpção, ${ }^{11}$ os resultados obtidos por meio do AUQEI indicaram que $61,53 \%$ das crianças possuem boa qualidade de vida e $38,46 \%$ foram classificadas como "prejudicadas". Os escores médios totais das crianças estudadas oscilaram de 41 a 54.

Para a análise das questões objetivas do AUQEI, somaram-se os escores médios de cada componente da escala, de forma independente, tendo-se verificado que o perfil da respostas obtidas mostra satisfação elevada para os itens concernentes a: Questão 09 "quando você pratica um esporte" - 36 pontos; Questão 11 "no dia do seu aniversário" - 35 pontos; e Questão 13 "quando você pensa em sua mãe" - 35 pontos (Gráfico 1).

Associa-se a esses resultados o valor que as atividades de lazer têm para crianças, implicando diretamente a qualidade de vida, tendo sido o item mais significativo. A necessidade de brincar não deve ser eliminada quando as crianças adoecem ou estão hospitalizadas, uma vez que a brincadeira desempenha papéis importantes, como a capacidade de sentirse mais segura em local estranho, com pessoas desconhecidas.
Em continuidade ao resultado da análise isolada das questões, foi possível identificar o fato de que os itens com os mais baixos escores foram referentes à: Questão 14, "quando você fica internado no hospital" - 6 pontos; e Questão 23, "quando você está longe da sua família" - 5 pontos (Gráfico 1).

A criança tem dificuldade de lidar com essa dinâmica hospitalar, percebendo-se isolada de tudo o que lhe é seguro. Os pais são seus tradutores no mundo do hospital, estão ligados pelo afeto, tornando-se a presença deles primordial.

Para a análise, foram somados os escores dos itens e foi calculada sua média, com o intuito de comparação. As dimensões em ordem crescente pela média da pontuação foram: Autonomia (14.4), Função (23.8), Família (27.2) e Lazer (33).

Pode-se observar ainda que as questões referentes à dimensão "Autonomia" foram as mais prejudicadas, com o menor índice, comparativamente aos demais. Apenas uma obteve escore satisfatório, todas as outras receberam pontuação de 13 e uma de 5 . É notável ser esse fator o que mais compromete a qualidade de vida da criança renal crônica. É reflexo das dificuldades impostas pela doença, que repercutem diretamente nas atividades comuns à infância, como o ato de brincar.

Um estudo ${ }^{18}$ indica que as doenças crônicas repercutem diretamente na autonomia da criança, principalmente durante a transição para a adolescência, pois nesta idade é que são desenvolvidas mais atividades fora de casa e do alcance dos pais.

Gráfico 1. Escores das questões do instrumento AUQUEl aplicado em crianças com diagnóstico de insuficiência renal crônica. Fortaleza - Ceará, 2008.

\section{Pontuação das Questões}

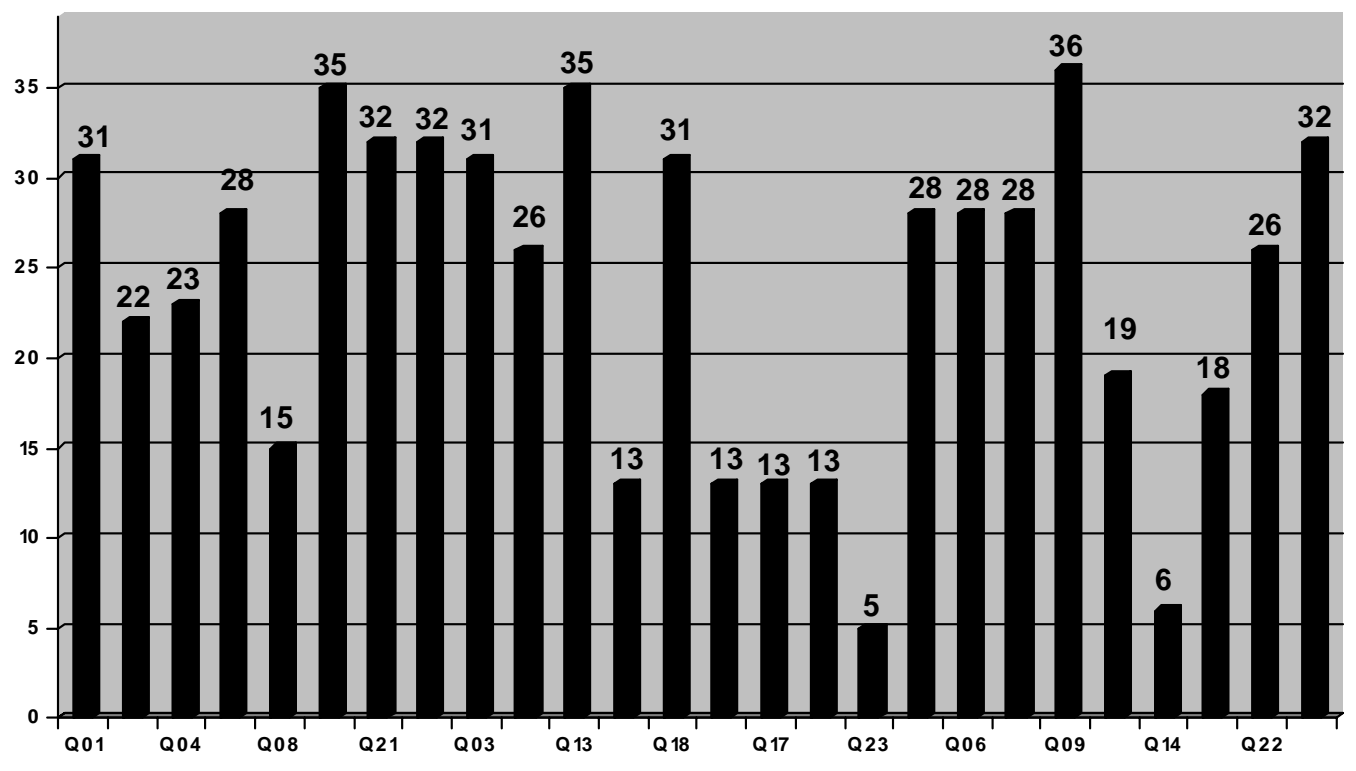




\section{CONSIDERAÇÕES FINAIS}

A criança com insuficiência renal crônica experimenta a complexidade da vivência com esse diagnóstico, da obrigatoriedade da adesão à tríade terapêutica - diálise, dieta e drogas medicamentosas - para manutenção da vida, sendo uma experiência diferente das demais crianças.

Ao se dar voz à criança, percebe-se a repercussão da doença em sua vida, os problemas inerentes à vivência com a cronicidade, sendo só ela capaz de relatar a sensação subjetiva de bem-estar, para assim avaliar a sua qualidade de vida.

Identificam-se, nos relatos, experiências comuns, que incluem dor no momento da diálise, caracterizado por diversas punções venosas, mudança de cateteres dentre outros, bem como o conflito da hospitalização, limitações que a doença e o tratamento proporcionam, como 0 ato de brincar e estudar, todos interligados em uma só expectativa, que leva à felicidade, um transplante adicionado ao valor que a família representa.

Os resultados do AUQEI quantitativo corroboraram os resultados subjetivos, pois indicam que a dimensão mais prejudicada foi a autonomia, sinalizando para a necessidade do desenvolvimento de ações em que a criança possa se sentir mais independente, capaz de realizar atividades do cotidiano, relacionadas, principalmente, ao lazer, uma vez que foi a dimensão mais valorizada para a criança. A família foi percebida como fonte de bem-estar para a promoção da qualidade de vida, não somente por obter a segunda média de escore mais elevada, mas também por ter sido considerada como basal a presença dela nos relatos.

A avaliação da qualidade de vida sugere que, muito além das expectativas dos outros, e/ou das dificuldades, a criança com insuficiência renal crônica, em sua percepção de mundo, é feliz, apesar de suas limitações e das inúmeras complicações a que está sujeita.

\section{REFERÊNCIAS}

1. Trentini M, Corradi EM, Araldi MAR, et al. Qualidade de vida de pessoas dependentes de hemodiálise considerando alguns aspectos físicos, sociais e emocionais. Texto\& Contexto Enferm 2004; 13(1): 74-82

2. Sociedade Brasileira de Nefrologia [site na Internet]. Censo 2007. [citado 5 jul 2008] Disponível em: http://www.sbn.org.br/

3. Barbosa LMM, Andrade Júnio MP, Bastos KA. Preditores de qualidade de vida em pacientes com doença renal crônica em hemodiálise. J Bras Nefrol 2007; 29(4): 222-29.

4. Caetano JA, Soares E. Qualidade de vida de clientes pós-infarto agudo do miocárdio. Esc Anna Nery Rev Enferm 2007; 11(1): 30-37.

5. Orlandi FS. 0 idoso renal crônico em hemodiálise: a severidade da doença e sua relação com a qualidade de vida. J Bras Nefrol 2008; 30(4): 245-50
6. Diniz DP, Romano BW, Canziani MEF. Dinâmica de personalidade de crianças e adolescentes portadores de insuficiência renal crônica submetidos à hemodiálise. J Bras Nefrol 2006; 28(1): 31-38

7. Deslandes SF. Humanização dos cuidados em saúde: conceitos, dilemas e práticas. Rio de Janeiro (RJ): Fiocruz; 2006.

8. Minayo MCS, HartzZMA, Buss PM. Quality of life and health: a necessary debate. Cienc Saude Col 2000; 5(1): 7-18.

9. Lakatos EM, Marconi MA. Fundamentos da metodologia científica. $6^{\text {a }}$ ed. São Paulo (SP): Atlas; 2005.

10. Ministério da Saúde (BR). Projeto Minha Gente. Estatuto da Criança e do Adolescente. Brasília (DF); 1991.

11. Assumpção FBJ, Kuzynski E, Sprovieri MH, et al. Escala de avaliação da qualidade de vida (AUQEI-Autoquestionnaire qualité de vie enfant imagé): validade e cinfiabilidade de uma escala para qualidade de vida em crianças de 4 a 12 anos. Arq Neuropsiquiatr 2000; 58(1): 119-27.

12. Minayo MCS. 0 desafio do conhecimento: pesquisa qualitativa em saúde. São Paulo (SP): Hucitec; 2004.

13. Bellodi PL, Romão Junior JE, Jaocmim A. Criança em diálise: estudo das características de personalidade através de técnicas projetivas. J Bras Nefrol 1997; 17(2): 132-37.

14. Faquinelo $P$, Collet N. Vinculo afetivo mãe-crianca na unidade de alojamento conjunto pediátrico. Rev Gaucha Enferm 2003; 24(3): 294-304.

15. Sager F, Sperb TM, Roazzi A, Martins FM. Avaliação da interação de crianças em pátios de escolas infantis: uma abordagem da psicologia ambiental. Psicol Reflex Crit 2003; 16(1): 203-15

16. Grespan SV, Regina PS, Masuco N. 0 transplante renal sob a ótica de crianças portadoras de insuficiência renal crônica em tratamento dialítico: estudo de caso. Acta Paul Enferm 2005; 18(3): 294-300.

17. Constituição da Republica Federativa do Brasil, 5 de outubro de 1988. Brasília (DF): Senado; 1988.

18. Queiroz MVO, Dantas MCQ, Ramos IC, et al. Tecnologia do cuidado ao paciente renal crônico: enfoque educativo-terapeutico a partir das necessidades dos sujeitos. Texto\& Contexto Enferm 2008; 17(1): 55-63

19. Eiser C, Morse R. Can parents rate their child's health-related quality of life? Results of a systematic review. Qual Life Res 2001; 10: 347-57 